\title{
Limitações processuais e critérios jurídicos ao controle jurisdicional do orçamento público
}

Procedure limitations and legal criteria to judicial control of public budget

Pedro Germano dos Anjos ${ }^{1}$

\begin{abstract}
Resumo
0 artigo analisa o exercício do poder estatal no que concerne ao atendimento das necessidades públicas ínsitas na Constituição Federal de 1988, bem como as infraconstitucionais, através da escolha regrada constitucionalmente e no nível orçamentário. Especificamente, 0 autor expõe limitações processuais e outros critérios, com o fito de demonstrar um racional e limitado poder de controle jurisdicional sobre a lei orçamentária. 0 cuidado que os aplicadores do Direito devem possuir face a toda concessão constitucional de poder deve ser um compromisso em relação ao mesmo controle judicial.
\end{abstract}

Palavras Chave: Orçamento; Necessidades Públicas; Deveres Estatais; Limitações Processuais.

\begin{abstract}
This article analyzes the exercise of power state in meeting the public needs inherent in the Constitution of 1988 and in the infra, by constitutional rule choice and budget level. Specifically, the author exposes procedural limitations and other criteria, he aims to demonstrate a rational and limited judicial control power over the budget bill law. The care that the law enforcers should have the in front of all the grant constitutional of power must be a compromise compared to the same judicial control.
\end{abstract}

Keywords: Budget; Public Needs; Duties Aid; Procedural Limitations.

\section{Introdução}

A possibilidade de controle judicial da execução orçamentária não configura ingerência nem usurpação de poder. A questão tem sido tratada como a efetividade de

\footnotetext{
${ }^{1}$ Bacharel em Direito pela Universidade Estadual de Santa Cruz - UESC/BA, M estrando em Direito Público pela Universidade Federal da Bahia - UFBa. Pós-graduando em Direito Tributário pelo Instituto Brasileiro de Estudos Tributários - IBET. Pesquisador vinculado à Fundação de Amparo à Pesquisa do Estado da Bahia FAPESB.
}

Revista de Direito Público, Londrina, v, 4, N. 2, P. 99-116, maio/ago. 2009. 
direitos fundamentais no campo processual e orçamentário, muito embora a visão atual faça prevalecer apenas o discurso ideológico da exigibilidade a qualquer custo dos direitos.

Esquece-se da ratio das leis orçamentárias, e todo o sistema rígido de Finanças Públicas na Constituição de 1988: o planejamento e a gestão compõem a atividade financeira do Estado (PASCOAL, 2004, p. 02), frente à receita pública e a obrigatoriedade constitucional em despender.

Os deveres do Estado, principalmente em relação aos direitos fundamentais, são resultado de modais deônticos das normas interpretadas do texto constitucional, obtendo eficácia plena como princípios, já que tais deveres não descrevem a conduta prescrita (ÁVILA, 2007, p. 72), caracterizando-se como comandos de otimização.

Desse modo, para os fins serem atingidos, é indispensável a realização de determinadas condutas pelo Estado:

[...] os princípios exigem a promoção de um estado de coisas - bens jurídicos - que impõe condutas necessárias à sua preservação ou realização. Daí possuírem caráter deôntico-teleológico: deôntico porque estipulam razões para a existência de obrigações, permissões ou proibições; teleológico porque as obrigações, permissões e proibição decorrem dos efeitos advindos de determinado comportamento que preservam ou promovem determinado estado de coisas (ÁVILA, 2007, p. 72).

Assim, Ávila defende que princípios são normas do que deve ser e estabelecem uma espécie de necessidade prática: prescrevem um state of affairs que só será realizado se determinado comportamento for adotado.

Essas condutas que devem ser se dão, obrigatoriamente, através da atividade financeira estatal. As necessidades públicas são normativas (decorrem da interpretação dos textos constitucionais) e devem ser, pelos princípios constitucionais, consideradas pelas leis orçamentárias, instrumentos de atuação estatal.

O controle do Orçamento e da sua execução, pois, é possível conforme a própria Constituição Federal. As leis orçamentárias são obrigatórias e as transferências correntes com o fito de satisfazer determinadas necessidades são deveres (decorrentes de regras) e não podem ser obstaculizados. Logo, um orçamento que não preveja essa satisfação (de, diga-se, necessidades constitucionais) não atende os seus propósitos.

Se há descumprimento dos propósitos para o qual o órgão foi criado (fundamento 
de existência de determinado poder, segundo sua competência), o órgão deve ser controlado por alguma instância. Se a interpretação dos textos normativos indica deveres, indica poderes de controle. É a sanção institucional, lato sensu.

Trata-se da identificação, segundo os moldes de nossa Constituição, de uma competência que tem sido relegada à discricionariedade administrativa ou confundida com ativismo judicial. Na exposição de critérios e limites, pois, um controle jurisdicional poderá ser melhor teorizado e aplicado.

No entanto, o controle mesmo constitui um poder, e como todo poder sem controle é poder em excesso, há que se cuidar para coibi-lo.

O Tribunal de Justiça de Santa Catarina adverte para o cuidado com a ditadura do Judiciário, na esteira de Rodolfo Mancuso:

Caberá ao Judiciário agir com engenho e arte para outorgar a tutela adequada aos interesses difusos, em convivência harmoniosa com as competências reconhecidas aos outros dois Poderes, neutralizando, assim, a imputação de um 'governo di giudici ' $\left[\ldots . . .{ }^{2}\right.$

Tal questão também foi abordada por Barcellos (2002, p. 14), in verbis:

Em um Estado Democrático, não se pode pretender que a Constituição invada o espaço da política em uma versão de substancialismo radical e elitista, em que as decisões políticas são transferidas, do povo e de seus representantes, para os reis filósofos da atualidade: os juristas e operadores do direito em geral.

Desse modo, há de se ter um conjunto de parâmetros, critérios e limites ao controle judicial, com o fito de este não se constituir em "atividade executiva togada", com seus intrínsecos abusos.

\section{Limites processuais e "condições da ação"}

Tomando como hipótese a possibilidade de um controle judicial na execução do orçamento público, mister se faz analisar critérios a serem usados e limites a serem seguidos pelos magistrados (ou, como veremos, critérios-limites).

Necessita-se, pois, de um contributo para o exercício jurisdicional do controle

\footnotetext{
${ }^{2}$ TJSC, Terceira Câmara Cível, em votação unânime. Apelação Cível n. 44.569, Relator Desembargador Eder Graf. Publicação em 17/02/1994.
} 
orçamentário, o qual não se arvora em ser exaustivo, mas expressa o dever de todo estudioso em demonstrar meios à aplicação prática do que se expõe em teoria.

Primeiramente, há que se lembrar das regras processuais, pois o processo constitui o instrumento do Poder Judiciário de atuação. Está-se diante do critério da substitutividade ou subsidiariedade.

Por ele, aplicam-se as regras da demanda e da correlação, inscritas respectivamente nos arts. 262 e 460, do Código de Processo Civil Brasileiro, formulados nos brocardos latinos ne procedat iudex ex officio e ne eat iudex ultra vel extra petita partium, como demonstra MOREIRA (1998, p. 10).

Há um limite para a atuação espontânea do Juízo, pelo que esse só pode funcionar em sendo provocado, ao tempo em que a decisão final deve ser correlata ao pedido, não o extrapolando (não pode conceder tutela para além dos direitos sociais).

O controle deve ser substitutivo, ocorrendo somente quando houver omissão pelos demais Poderes na implementação de direitos sociais previstos em Leis Orçamentárias, ou atuação de medidas claramente desproporcionais ao seu atendimento.

Além de tais regras processuais, podem ser analisados o interesse, a legitimidade e a possibilidade jurídica do pedido na hipótese de ação do Poder Judiciário contra o arbítrio do Poder Executivo no munus público, no plano de gastos governamentais. ${ }^{3}$

Esmiuçando-se 0 interesse de agir, a necessidade sempre existe quando direitos fundamentais estejam sendo desrespeitados. Di Pietro (2005, p. 655) observa que todo desrespeito a direito individual ou coletivo enseja controle jurisdicional do ato administrativo, tendo como existente 0 interesse de agir sempre que se prove a lesão. Observa-se assim que uma via processual adequada é a Ação Civil Pública, pelo Ministério Público ou Defensoria Pública.

Vislumbra-se, por outro lado, mais um cabimento do Mandado de Segurança, já que o desvio injustificado de recursos de uma dotação escolhida segundo a lei orçamentária para outra não prevista ou de necessidade menor constitui ilegalidade de autoridade pública. É

\footnotetext{
${ }^{3}$ Há uma tendência geral dos procuradores dos entes administrativos em apontar a falta da 'condição' da ação 'possibilidade jurídica do pedido' ao se invocar a discricionariedade administrativa, já que seria 'impossível' ao Poder Judiciário se imiscuir na conveniência e oportunidade do pedido. Trata-se de uma, como repetido, falácia. Isso porque o pedido fundado no dever do Estado segundo ditames constitucionais e na vinculação 'fraca' das dotações orçamentárias é tarefa mesma do Poder Judiciário, dado este como um dos guardiões da Carta Magna e da Lei. É questão de aplicação da CF e das leis, e isso é função jurisdicional.
} 
perfeitamente utilizável o mandamus, uma vez em se concordando no efeito de lei material das leis orçamentárias.

De outro modo, em sede de legitimidade, o Ministério Público e a Defensoria Pública possuem prerrogativa constitucional para ser pólo ativo da ação (seja ACP ou MS), na defesa de interesses difusos, como o são os interesses de toda uma população frente à utilização dos gastos públicos no atendimento das necessidades sociais.

Ademais, somente o Parquet ou a Defensoria podem criar oportunidade de controle judicial orçamentário, justo porque titularizam meios suficientes para a instrução da investigação civil, a produção da provas, requerimento de peças, atuação destemida perante autoridades públicas, dentre outros.

Não se está negando a possibilidade de um particular questionar as contas públicas. Trata-se de um reconhecimento pragmático dos citados órgãos públicos essenciais ao exercício da jurisdição como sujeitos hábeis para propor alteração de despesa pública ou mesmo a aplicação de uma dotação orçamentária (quando se tratar de omissão), na defesa de um interesse público, o que decorre de suas funções institucionais.

0 particular pode recorrer à Ação Popular, quanto à proteção do erário público, quando perceber uma despesa que não possui razão de ser, por não se encontrar entre a satisfação de uma necessidade pública qualquer, ou em caso de desvio de finalidade explícito.

Possibilidade jurídica do pedido e sumarização horizontal da cognição: controle legal

A possibilidade jurídica do pedido requer, porém, maior atenção, com o fito de não se permitir usurpação de poder pelo Judiciário na atuação do controle.

Desse modo, entendemos que o objeto do controle jurisdicional deve ser limitado e nisso está o verdadeiro cuidado para não se preconizar um governo 'di giudicci', obviamente atentatório à Constituição.

Para enfrentar o tema, analisemos Acórdão do Tribunal de Justiça do Rio Grande do Sul: ${ }^{4}$

${ }^{4}$ TJRS, Sétima Câmara Cível. Apelação Cível n. 596017897. Relator: Sérgio Gischkow Pereira. Julgamento em 12/03/ 1997. 
[...] Norma constitucional expressa sobre a matéria e de linguagem por demais clara e forte, a afastar a alegação estatal de que o Judiciário estaria invadindo critérios administrativos de conveniência e oportunidade e ferindo regras orçamentárias. Valores hierarquizados em nível elevadíssimo, aqueles atinentes a vida e a vida digna dos menores. Discricionariedade, conveniência e oportunidade não permitem ao administrador se afaste dos parâmetros principiológicos e normativos da Constituição Federal e de todo o sistema legal [...].

A redação do trecho jurisprudencial acima colacionado nos remete, pois, a campo interessante para definirmos o objeto imediato da atuação jurisdicional, afora os limites processuais acima delineados. Que valores "em nível elevadíssimo" seriam esses? Os atinentes à vida e à vida digna? Os direitos postos na Constituição Federal, de maneira ampla?

Tais questões são respondidas pela ratio que permeia a instituição das leis orçamentárias em nível constitucional e por um classificação das necessidades públicas que tenha em conta a importância social da execução das despesas públicas com força constitucional (ANJOS, 2008, p. 2375-2388). ${ }^{5}$

Seria impossível, no mínimo confuso, executar um controle jurisdicional dos atos de execução orçamentária tendo por base todos os direitos positivados na Constituição. Fato é que a sociedade tem múltiplas carências as quais não podem ser atendidas todas de pronto, mesmo por um Administrador idôneo e competente.

Pois bem, nesse panorama angustioso, perceba-se a instituição pela Carta Magna da obrigatoriedade das leis orçamentárias. As leis orçamentárias planejam despesas e prevejam receitas, dispondo sobre a utilização do erário público com um único fim: a satisfação de determinadas necessidades públicas, indicadas pelo Poder Executivo e aprovadas pelo Legislativo.

Ora, pressupondo 0 atendimento, pelo menos em fase de elaboração e aprovação do Plano Plurianual, da Lei de Diretrizes Orçamentárias e da Lei Orçamentária Anual aos princípios constitucionais prioritários para determinada comunidade, o controle jurisdicional dos atos de execução orçamentária deve se limitar, ademais, aos direitos subjetivos públicos expostos nos referidos instrumentos legais.

Desse modo, o controle seria de legalidade, no sentido de que o Poder Judiciário

\footnotetext{
${ }^{5}$ Há possibilidade de uma classificação das necessidades públicas constitucionais, chegando a três espécies, quais sejam, as em sentido estrito (necessidades básicas), as úteis (de utilidade média) e as de mera permissão constitucional condicionada (possibilidade regrada).
} 
possui legitimidade para reexaminar atos de outrem com fulcro em instrumento legal: em cada caso, pode reexaminar atos de despesa pública que supostamente não sejam consentâneos com as leis orçamentárias. Ainda e principalmente, omissões do Executivo a deveres jurídicos do Estado impostos especificamente nas leis orçamentárias e genericamente na Carta Magna.

Assim é o limite quanto ao objeto, devendo este ser a defesa dos direitos sociais e econômicos duplamente positivados: primeiro, em nível constitucional; segundo, em sede orçamentária.

Perceba-se que essa limitação, além de dizer respeito à possibilidade jurídica do pedido, toca a legitimidade processual passiva: sendo dever do Estado, a Fazenda Pública tem legitimidade passiva para responder por omissões aos dispositivos orçamentários; e sendo os dispositivos orçamentários baseados na Constituição, são exigíveis como direitos sociais, possível e forçosa a atuação do Judiciário para implementá-los.

Enfim, o pedido é possível, não obstante a defesa falaciosa da discricionariedade administrativa e da ingerência de poder. A discricionariedade, como visto, tem seu momento certo em se tratando de despesa pública, sendo que na execução orçamentária se refere à forma legal e a possibilidade de escolha dos meios, não abarcando a escolha do agir ou não agir. Não é apenas possível, mas necessária, a atuação jurisdicional com o fito de resguardar preceitos constitucionais e legais orçamentários.

De outro lado, ao verificar a possibilidade do pedido somente no que toca aos direitos prestacionais da Constituição Federal que forem positivados nas leis orçamentárias, vislumbra-se a sumarização horizontal da cognição. Explique-se.

Segundo Câmara (2004, p. 278-281), há dois grandes gêneros de cognição sumária, a horizontal e a vertical. A primeira diz respeito ao objeto processual, ou seja, a delimitação ou não dos pontos da demanda naturalística que podem ser conhecidos. Divide-se em plena, quando se conhece todos os elementos componentes do objeto da cognição, e limitada, quando ocorre alguma restrição na amplitude da cognição.

Já a segunda se refere ao nível de profundidade em que será exercida a cognição pelo Juízo sobre todo o objeto do processo, e se divide em rarefeita ou superficial, sumária (sentido estrito) e exauriente.

Interessa-nos o primeiro gênero, a cognição sumarizada horizontalmente, que tem 
como grande exemplo as ações possessórias, nas quais não se pode analisar o domínio.

Na medida em que o Juízo, baseado em premissas constitucionais, se debruça sobre as questões orçamentárias, há forte tendência em se exigir do Estado-Administração o pronto atendimento às necessidades reais dos administrados.

No entanto, as disposições constitucionais sobre direitos prestacionais dos cidadãos e sobre deveres do Estado são muito amplas, assim como as complexas necessidades públicas de cada Município e suas peculiaridades.

Isso sem contar a atuação do princípio da escassez, pelo qual há sempre menos recursos e mais e variadas necessidades das pessoas de uma localidade.

Em vista disso, poderiam aventar que o Magistrado poderia eleger por si próprio as necessidades mais urgentes de certa localidade para serem atendidas prioritariamente, relegando outras necessidades a serem satisfeitas de modo subsidiário.

Todavia, tal atividade perpetrada por um Magistrado só levaria à infringência do princípio democrático, passando o Juiz a gerir a receita pública do modo que lhe aprouver.

Ululante que a eleição dos políticos, por mais incompetentes que sejam muitos deles, não dá azo à atuação dos Magistrados como 'novos reis filósofos' (BARCELLOS, 2007, p. 14), sendo o Direito como Direção Social apenas no tocante às opções políticas constitucionais, as quais devem ser respeitadas não só pelos Juízes, mas pelos Administradores, primeiramente.

Quer com isso dizer-se que no controle judicial orçamentário há cognição sumarizada horizontalmente, ou seja, limita-se o objeto da demanda posta em juízo para que seja analisada somente no tocante às disposições constitucionais que estiverem representadas nas leis orçamentárias ou às disposições manifestamente desproporcionais com a moralidade pública (art. 37, caput).

Como dito, não poderia se previr ampla liberdade na escolha das necessidades públicas a serem satisfeitas pelo Juiz tão-somente. A iniciativa da Lei orçamentária deve ser respeitada, assim como os processos de preferência já tomados (conceitos que veremos adiante) pelo Poder Executivo e emendado pelo Poder Legislativo.

Ademais, a cognição assim sumarizada oportunizará rapidez e serenidade para 0 Poder Judiciário, bastando que os M agistrados tenham intimidade com o processo legislativo orçamentário e sejam informados pelos autores do dissídio (o Ministério Público ou 
Defensoria Pública) acerca do cumprimento efetivo das rubricas orçamentárias cujo objetivo seja a satisfação das necessidades em sentido estrito (vitais básicas).

\section{Tutela jurisdicional em sede de controle orçamentário}

Outro limite a ser observado é quanto ao tipo de tutela: esta deve ser sempre a específica. Perdas e danos não se resolvem de modo algum em sede de controle orçamentário, mesmo porque para tanto há de se seguir 0 art. 100 da CF (precatórios).

Por outro lado, não se pode confundir o controle judicial orçamentário aqui preconizado com os instrumentos de controle judicial na área penal, instituídos pela polêmica Lei de Responsabilidade Fiscal (LC №. 101/2000).

A visão repressiva do Direito, nesse passo, tem que deixar lugar a uma função promocional. Não como a função promocional preconizada por Bobbio (2007), mas como uma função que se volta à efetividade de direitos sociais, por revelarem um mínimo existencial, doador de cidadania legítima aos indivíduos.

A tutela específica aqui referida é quanto ao controle judicial indicar a efetiva prestação de serviço público determinado em lei orçamentária, baseando-se em uma necessidade pública básica, que não pode ser procrastinada.

Independe de se tratar de ação ou omissão do Executivo: a rubrica orçamentária é exigível quando possui força constitucional, ou seja, revele-se básica ou, quando muito, emergencial.

Assim, preconiza-se uma ordem mandamental ao ente público que se omite em cumprir dispositivos legais orçamentários de força constitucional ou, mesmo, não se presta a atender necessidades surgidas em estado emergencial (baseadas essas no artigo sexto de nossa Carta M aior).

Analisados os limites processuais e materiais do controle a ser exercido em sede de execução orçamentária, parte-se para a instituição de critérios em rol meramente exemplificativo, como um contributo racional para o exercício do controle, baseado em elementos objetivos de atuação. 


\title{
Critérios-limites para o exercício do controle
}

A par dos limites processuais de intervenção judicial na esfera orçamentária está a possibilidade, de acordo com a teoria econômica vigente, de se conhecer um "gasto público ótimo".

Nesse sentido, e sabendo que "o liberalismo de processo pleno é a referência fundamental e historicamente central da ética econômica e social do mundo moderno" (KOLM , 2000, p. 125), é o entendimento de Serge-Christophe Kolm (2000, p. 130):

\begin{abstract}
A teoria do Contrato Social Liberal nos permite determinar o funcionamento e as estruturas institucionais do setor público liberal de processo pleno. Estas incluem 0 princípio geral da tributação dos lucros para os bens públicos; [... ] a teoria do gasto público como retro pagamento (retrocompras e "retrodoações") e da determinação do gasto público ótimo; [...]. (grifo nosso)
\end{abstract}

Ao lado de tais reflexões sobre a otimização do gasto público, resta reconhecer que, não obstante ser possível um controle judicial sobre os atos de execução orçamentária, no sentido de uma judicial review, necessário delimitar critérios para o seu exercício. É preciso que a máxima "poder sem controle é poder em excesso" seja aplicada ao próprio poder de controle judicial.

A exigência causal decorrente da máxima acima é o estabelecimento de critérios sobre os quais toda e qualquer intervenção judicial na execução do orçamento público deverá seguir, seja para encontrar o gasto público ótimo, seja para se frustrar a existência de "déspotas togados".

Nessa esteira de intelecção que se deve debruçar em certos critérios, ou mais propriamente critérios-limites, pois ao mesmo tempo em que orientam a intervenção, funcionam como limitadores da mesma.

Primordialmente, vale colacionar a exposição de Aliomar Baleeiro que, antes de dizer sobre o critério político da decisão de gastar, analisou o "princípio da máxima vantagem social", enfatizando sua semelhança com a teoria dos marginalistas. Essa exposição merece ser propagada, mesmo que resumidamente.

A máxima vantagem social parece ser encontrada como a utilidade marginal: em determinados pontos, "é mais vantajoso para a coletividade que os recursos disponíveis, através do dinheiro, sejam transferidos da utilização privada para a utilização pública." 
(BALEEIRO, 2006, p. 77) lembra a alusão de Hugh Dalton:

Os impostos asseguram maior proveito para a coletividade, que através deles pode ampliar escolas ou hospitais etc., embora com isso algumas damas exibam apenas quatro e não seis vestidos, como antes, nas famosas corridas de Asco.

Assim, Aliomar Baleeiro o aponta como uma das regras racionais em que devem se inspirar os governantes, muito embora vários fatos provem que, não raro, as deliberações são irracionais.

Também Kolm (2000, p. 561) nos escreve sobre teorias que buscam ótimo social, valendo trazer a lume a Teoria da Escolha Social, um "utilitaromorfismo" (por basear-se, em parte, na teoria utilitarista) que "apresentou-se declarando que buscava encontrar a solução para o problema geral do ótimo social".

O próprio autor a critica, aduzindo que a lógica dessa teoria não serve para induzir ao ótimo social, pelo excesso de hipóteses falsas. No entanto, ele mesmo confessa que (KOLM , 2000, p. 536-537):

[... 0 uso da racionalidade e de princípios para resolver um problema pode exigir a consideração hipotética de problemas inexistentes e que eles o exigem quando existe apenas um problema efetivo.

Assim, passemos a analisar um pouco de tal teoria, segundo as próprias palavras do referido autor:

A escolha social geral está dividida de facto em escolhas específicas, algumas bastantes gerais, como a escolha de um orçamento nacional, outras locais, até as interações entre duas pessoas. Cada interdependência - e, sobretudo, cada oposição entre os interesses ou valores de muitas pessoas - dá origem a uma situação de escolha social, possivelmente com coordenação, aplicação de normas e respeito pela justiça. Contudo, deve-se enfatizar que a escolha social geral nada mais é que o conjunto de todas as escolhas sociais específicas. Portanto, o ótimo para a escolha social geral nada mais é que o conjunto de ótimos para todas as escolhas sociais específicas (KOLM, 2000, p. 559).

Assim é que se entende a origem da imprescindível escolha das necessidades públicas: os interesses e valores são infinitos e de muitas pessoas, cabendo a cada um (em sede de ordenamento individual) e a cada sociedade (no seu respectivo ordenamento social) escolher alguns destes interesses para serem atendidos de maneira privilegiada. 
Não por serem necessidades "mais importantes" em termos absolutos, mas porque assim é a contingência da escolha e bem assim a visão de mundo do homem, sempre contingente. Tal modo de pensamento remonta à economia, no raciocínio de que os bens da vida são escassos frente à demanda das muitas pessoas.

De outro lado, o trecho colacionado indica a importância das escolhas sociais específicas, de modo que o ótimo social se vislumbra do cumprimento às mesmas. Logo, como tais escolhas estão no bojo das leis orçamentárias, necessário dizer que o documento pelo qual o controle deve agir é a Lei Orçamentária Anual, interpretada imediatamente de acordo com a LDO e o PPA e mediatamente pela Constituição Federal.

\section{Primeiro e segundo estágio do controle}

Evidencia-se a lei orçamentária como um objeto-limite, na medida em que contiver em seu bojo as dotações de força constitucional, a dizer, as dotações de despesa que visem satisfazer alguma necessidade pública em sentido estrito (vitais básicas).

Nesse passo, a identificação das dotações de força constitucional torna-se imprescindível. Evidenciado no Inquérito Civil a cargo do Ministério Público ou da Defensoria Pública, ${ }^{6}$ que as circunstâncias de fato apontam uma carência básica de nenhum modo remediada pela Administração, surge o primeiro estágio do controle: análise da Lei Orçamentária no que concerne à satisfação das necessidades básicas.

Sem penetrar na ampla discussão sobre o tema, mas com o intuito de referir a uma justificação constitucional das necessidades básicas, mister dizer sobre a dignidade humana, como preocupação mundial e jurídica. Resta saber e delimitar o que é dignidade e por conseqüência o princípio constitucional erigido como fundamento do Estado democrático de direito.

Bem se fala que esse princípio tem sido usado para fundamentar todo e qualquer argumento jurídico, mas não se sabe delimitar a sua esfera exata e plausível de atuação. No

\footnotetext{
${ }^{6}$ Ambos são órgãos essenciais ao exercício da função jurisdicional e a Defensoria possui legitimidade em se tratando de ACP, com base na Lei $\mathrm{n}$ ‥ 11.448/2007, art. 50, II. Alguns ainda dizem que tal dispositivo é inconstitucional, porque a Defensoria só poderia atuar em se tratando de necessitados. Isso está em nítido descompasso com o princípio da cooperação de todos os órgãos estatais e com a própria atribuição à Defensoria no que concerne à Curadoria de ausentes, necessitados ou não. O M P não perdeu poder, e sim angariou um agente cooperador na defesa de interesses da coletividade, até porque, em se tratando de Brasil, a maioria da coletividade é sempre 'necessitada'. A cooperação é precípua e urgente, o litisconsórcio sempre será bem-vindo, sem hipocrisias de classe, inaceitáveis em um Estado de Direito.
} 
entanto, no que concerne ao orçamento, a dignidade humana está subentendida na adequada alocação de recursos pelos Poderes Executivo e Legislativo com o fito de cumprirem o desiderato de promoção do mínimo existencial aos indivíduos.

A dignidade rege um maior valor às necessidades de sobrevivência e de desenvolvimento humano, e um desvalor implícito às demais necessidades que não se ligam diretamente aos cidadãos como seres humanos ou que somente se refiram a certos grupos oligárquicos (BARCELLOS, 2002, p. 245-246).

Remonta-se de elevada importância, assim, a classificação das necessidades públicas, tendo em conta que as chamadas vitais básicas, graduadas pelo mínimo vital, devem ter preponderância sobre as outras necessidades, de utilidade média e meramente regradas (ANJOS, 2008, p. 2385).

Diga-se desde logo que essa é uma regra geral inferida do princípio da dignidade humana em que se faz um corte axiológico entre termos (as necessidades), o que geralmente não se faz em se tratando do citado princípio.

Nesse sentido, o 'ótimo social' dantes referido está no plano do pressuposto constitucional de validade de dotação orçamentária, no que concerne ao plano global do Orçamento, em se atendendo mais as necessidades públicas básicas do que as demais. Não se trata de proibir as despesas com publicidade de maneira geral. Mas cabe determinar remanejamento de verbas para se atender a necessidades mais urgentes que sofrem omissão do Executivo e Legislativo.

Nesse passo surge a identificação do segundo estágio do controle: a análise de proporcionalidade e a razoabilidade nos processos de escolha das necessidades públicas a serem satisfeitas em determinado orçamento.

\section{Postulados de Proporcionalidade e Razoabilidade}

Segue-se aqui o entendimento esposado por Humberto Ávila. Segundo ele, a proporcionalidade e a razoabilidade são postulados normativos aplicativos. Não são princípios nem regras, pois estão em um âmbito diverso de tais normas: estão no nível da própria aplicação das normas (ÁVILA, 2007, p. 133-141). 
A razoabilidade é um postulado específico, que pode ser entendido em três acepções: como equidade (harmonização da norma geral com o caso individual), como congruência com a realidade e como equivalência.

No primeiro caso, a razoabilidade atua como instrumento para determinar que as circunstâncias de fato devam ser consideradas com a presunção de estarem dentro da normalidade. "A razoabilidade atua na interpretação dos fatos descritos em regras jurídicas", como a preservar a eficácia de princípios axiologicamente sobrevalentes.

No segundo, liga-se ao postulado da igualdade, pelo que na análise entre critério e medida evidencia-se a razoabilidade do critério discriminatório.

No terceiro, a razoabilidade exige equivalência entre a medida adotada e o critério que a dimensiona.

Já a proporcionalidade apenas se aplica a situações referentes a uma relação de causalidade entre dois elementos empiricamente discerníveis, um meio e um fim, de tal sorte que:

[...] se possa proceder a três exames fundamentais: 0 da adequação (o meio promove o fim?), o da necessidade (dentre os meios disponíveis e igualmente adequados para promover o fim, não há outro meio menos restritivo do(s) direito(s) fundamental(is) afetado?) e o da proporcionalidade em sentido estrito (as vantagens trazidas pela promoção do fim correspondem às desvantagens provocadas pela adoção do meio?) (ÁVILA, 2007, p. 161).

0 próprio autor salienta que o postulado da proporcionalidade cresce em importância no Direito Brasileiro, notadamente como instrumento de controle de atos do Poder Público. Por ele, um meio adequado é aquele que "promove minimamente um fim". Um meio é necessário quando "não houver meios alternativos que possam promover igualmente o fim sem restringir na mesma intensidade os direitos fundamentais afetados". E um meio é proporcional quando "o valor da promoção do fim não for proporcional ao desvalor da restrição dos direitos fundamentais" (ÁVILA, 2007, p. 182).

No que se refere ao Orçamento e um possível controle judicial, os postulados de razoabilidade e de proporcionalidade podem ser amplamente utilizados como critérios, com o fito de adequar as hipóteses de ocorrência do controle, bem como a sua extensão e exercício.

Explique-se. 0 controle judicial aqui referido deve se pautar pela razoabilidade: 
sempre analisar a relação entre medida e o critério de escolha, presumindo a regular situação de fato e o cumprimento do dever pela Administração, além de analisar equivalência entre a medida e o critério que a dimensiona.

Nesse sentido, a razoabilidade está nos processos de preferência, adiante explicados, servindo para a obstaculização ao cumprimento de dotações absurdas face 0 interesse público e para promoção de atividades concernentes ao mesmo, porém previstas e não cumpridas.

Um exemplo é a preferência de recursos à publicidade do governo em prejuízo da Educação ou da Saúde públicas.

No que toca ao postulado da proporcionalidade, o controle analisa as medidas a serem adotadas, cabendo sempre que os meios sejam manifestamente inadequados (como um aparelho de exames totalmente ultrapassado), ou haja outro meio menos restritivo que igualmente promova um fim com mais vantagens do que desvantagens.

Óbvio que a proporcionalidade e a razoabilidade dos gastos serão analisados caso a caso, sendo que a regra geral possível é tal que as básicas têm preponderância sobre as de utilidade média e essas sobre as de possibilidade regrada. Isso, ao tempo em que não se pode excluir a existência de nenhuma dotação orçamentária, em respeito ao princípio democrático, salvo se constituir em si mesmo um absurdo desproporcional.

Cabe dizer que os postulados podem estar viciados em dois âmbitos: qualitativo e quantitativo. Respectivamente à razoabilidade e à proporcionalidade, o qualitativo se liga à escolha de uma dotação ou medida absurda; o quantitativo, à alocação de recursos em excesso para dotações sem força constitucional ou de recursos exíguos para dotações de força constitucional.

Assim, um Orçamento que preveja uma dotação referente à compra de automóveis importados para servirem de carros oficiais, é qualitativamente desproporcional, pois a sua própria existência contrasta com a necessidade da medida. Enquanto milhões estão abaixo da linha da pobreza, os políticos eleitos escolhem os carros mais caros para trabalharem. 0 dinheiro público não pode servir desmedidamente ao puro conforto das autoridades. A necessidade pública de carros oficiais é de utilidade meramente instrumental, sendo mais proporcional a compra de carros confortáveis, porém, nacionais.

De outro lado, a dotação que prever o gasto de $R \$ 1.000 .000,00$ (um milhão de 
reais) para a construção de uma praça pública municipal de pequena proporção (fato real de Município do sul da Bahia) é quantitativamente desproporcional por excesso. A previsão de recursos exíguos para a Área da Educação, de outro modo, é desproporcional por não atender a necessidade e adequação de medida prioritária.

\section{Terceiro estágio}

Rapidamente, vale apontar um terceiro estágio para a cognição em sede de controle orçamentário, qual seja, a consulta aos órgãos de deliberação democrática como os Conselhos de direitos.

Longe de debater sobre a polêmica havida após a decisão do Superior Tribunal de Justiça nesse sentido, ${ }^{7}$ já apresentada nesse trabalho (Capítulo Primeiro), é notório o crescimento da importância atribuída aos Conselhos de direitos e demais entidades de participação democrática.

Significa participação democrática, e não pode ser olvidado, malgrado as vozes em contrário (que significaria ameaça à deliberação do Legislativo). Fato é que as entidades de participação democrática estão previstas em lei e geralmente são formadas por profissionais que lidam com as necessidades públicas. Portanto, são indicadas para, no mínimo, auxiliar a decisão jurisdicional em sede de controle dos gastos públicos.

\section{Conclusões}

Humberto Ávila afirma que o Poder Judiciário pode instituir controle dos atos dos outros Poderes, adstringindo-se a "avaliar a avaliação" feita por eles quanto à premissa escolhida e a razão justificadora,

[...] justamente porque o Poder legislativo só irá realizar ao máximo o princípio democrático se escolher a premissa concreta que melhor promova a finalidade pública que motivou sua ação ou se tiver uma razão justificadora para ter se afastado da escolha da melhor premissa (ÁVILA, 2007, p. 174).

Em sede de controle judicial possível da avaliação orçamentária realizada pelos poderes Legislativo e Executivo, sendo o juiz avaliador da avaliação, devem ser sustentados

\footnotetext{
${ }^{7}$ REsp 493811/SP. Rel. Min. Eliana Calmon. Segunda Turma. Data: 11/11/2003. DJ 15.03.2004, p. 236. RDDP, vol. 14, p. 120. Disponível em «www.stj.org.br>. Acesso em 21/08/2007.
} 
critérios-limite, para que a comunidade jurídica identifique os casos de excesso de poder, vez que os magistrados não são representantes diretos da sociedade.

Por outro lado, a organização constitucional rígida das finanças públicas reflete 0 dever em se respeitar as avaliações democráticas em sede orçamentária prévia, somente podendo ser afastadas caso não sejam razoáveis e proporcionais.

O controle possível, pois, detém limites processuais e lógico-jurídicos (BORGES, 1999, p. 95) que devem ser expostos e estudados pela Ciência do Direito em caráter universalizante. Esse o êxito desse singelo trabalho: iniciar a busca pela identificação e discussão de tais critérios.

\section{Referências}

ÁVILA, Humberto. Teoria dos Princípios: da definição à aplicação dos princípios jurídicos. $7 \underline{a}$ ed. São Paulo: M alheiros, 2007.

ANJOS, P. G., Natureza das Escolhas Orçamentárias: por uma classificação constitucional das necessidades públicas. Anais do XVII Encontro Preparatório para o Congresso Nacional do CONPEDI. p. 2375-2394. Florianópolis: Fundação Boiteux, 2008.

BALEEIRO, Aliomar. Uma introdução à Ciência das Finanças. 16a Ed. rev. e atualizada por Dejalma de Campos. Rio de Janeiro: Forense, 2006.

BARCELLOS, Ana Paula de. A Eficácia Jurídica dos Princípios Constitucionais, Rio de Janeiro: Renovar, 2002.

- Neoconstitucionalismo, Direitos Fundamentais e Controle das Políticas Públicas. Revista Diálogo Jurídico. Salvador, 2007. №. 15. Disponível no site www.direitopublico.com.br. Acesso em 09/08/2007.

BOBBIO, Norberto. Da Estrutura à Função: novos estudos de teoria do direito. Tradução de Daniela Beccaccia Versiani. Barueri - SP: M anole, 2007.

BORGES, José Souto M aior. Lançamento Tributário. 2a Ed. São Paulo: M alheiros, 1999.

CÂM ARA, Alexandre Freitas. Curso de Direito Processual Civil. vol. 1. 11aㅡ ed. rev. e atual. Rio de Janeiro: Lumen Juris, 2004.

DI PIETRO, Maria Sylvia Zanella. Curso de Direito Administrativo. 18 Ed, São Paulo: Editora Atlas, 2005.

KOLM, Serge-Christophe. Teorias M odernas da Justiça. São Paulo: Martins Fontes, 2000. 
M OREIRA, José Carlos Barbosa. 0 Novo Processo Civil Brasileiro. 19o edição, revista e atualizada. Rio de Janeiro: Forense, 1998. 